\title{
Psychological Analysis of Codependents
}

\author{
Yekaterina Raklova
}

Innovative University of Eurasia, Pavlodar

*Corresponding Author: katie777@mail.ru

Copyright (C) 2014 Horizon Research Publishing All rights reserved.

\begin{abstract}
This article considers general issues and the relevance of co-dependence, and the results of pilot study of wives and husbands who have alcohol problems are given . Under the co-dependence, we understand, a painful condition in real time, which is largely the result of adaptation to a family problem. Initially, this remedy or means of survival for the person in adverse family circumstances for him, a kind of anchored response to stress or alcohol addiction a loved one, which eventually becomes a way of life.
\end{abstract}

Keywords Symbiosis, Chemical Dependenc, Spiritual Development, Family, Suppressed Negative Emotions, Personality Changes, Lack of Morality, Isolation

\section{Introduction}

Considering the nature of codependency E. Young (1987) notes that a single, comprehensive definition of codependency does not exist, so we have to resort to a description of the phenomenology of this condition. The author believes that the external referent is manifested in the absence of boundaries. Codependent people do not know where the end of their personality and identity begins where the other person. Not having the ability to really feel their emotions, they are under very strong influence of the emotions that arise from other people (such as depression, anger, anxiety, anger, happiness, borrowing them from others). According to B. Hellinger, in the light of man appears in a small group - the family. Family relationships necessary for survival. They give the individual the opportunity to discover, promote personal growth, but at the same time forced to follow the goals that are not always considered his personal aspirations and desires. Therefore, in the reign relations order and the forces that both support and demand, urged on and correct, make happy and limited.

Considering the question of co-dependent state of the individual T. P. Korolenko and N.V. Dmitrieva (2001) refer to analyze the structure of co-dependence, and explains the reason for the difficulties of co-dependent people. According to them, no sense of boundaries of its own "I" makes it impossible for healthy functioning, a full contact with another person, as it leads to confusion, bias, and "absorption". Codependent people with vague boundaries tend to personalize everything happening around, seeing in this phenomenon, which has direct relevance to them [2]. They take responsibility for everything that happens. Experts that give the characteristics codependent individuals celebrate their dishonesty, their lack of morals. The lack of morality, according to N.V. Dmitrieva, due to the fact that the codependent weakly expressed spirituality, they are characterized by excessive earthiness, they forget about their children, taking care of them all comes down mainly to the control. His mother, however, remains emotionally unavailable to their children.

Codependency is a deviation in the development, directly caused by a dysfunctional, travmatiziruyuschim child rearing. This translates into insecurity and low self-esteem in this regard, the inability to establish a stable healthy relationships, both with himself and with others. In recent years, the national psychology, researchers' attention to the problem of co-dependence has increased significantly. "Until about the mid-90s of the twentieth century, national studies were quite fragmented, and their numbers were few." The latter years were marked by the publication of several monographs, dissertations, articles in specialized publications [3].

According to the OP Eliseev (1994), in psychology over the past forty years has published more than five thousand articles and books on all sorts of aspects of the analysis of the problem of anxiety, as one of the important characteristics of codependency. "This issue is considered by researchers from different perspectives: as a motive, and as an emotional state, and as a property and a personality trait, and so on." Nevertheless, the studies themselves are still quite a few "white spots" and trends waiting to be explored.

A small number of interpretations of codependency, available in both psychological and psychiatric literature indicate that there is no clear understanding of the nature of this phenomenon. Among the major provisions of the co-dependent state of the individual Moskalenko out the following, the desire to control the lives of others, to save, the distortion of the senses, negativism, the defeat of the spiritual realm. For a more complete understanding of codependency Moskalenko VD compares dependence and codependency, highlighting their common features. The generality of psycho-emotional and psychosomatic 
manifestations in the form of a powerful psychological defenses (denial, rationalization, etc.). Dependency and codependency leads to deterioration and degradation in the physical, mental, emotional and spiritual spheres, both of these states draw energy, health, thoughts and emotions [4].

\section{Materials and Methods}

As addiction, and codependency is a long-suffering, leading to deformation of the spiritual sphere. E. Smith believes that the codependent, this deformation is expressed in the fact that they love instead of hate fed to a close, lose faith in all but himself, even though its healthy momentum also do not trust, feeling a burning sense of jealousy, envy and despair. Mechanism for the manifestation of codependency E. Smith (1991) is a triad;

1) abscessing - subject to compulsive addiction,

2) the denial as a form of psychological protection,

3) loss of control,

The main symptoms of codependency include:

1) a sense of their dependence on men;

2) the feeling of being trapped in degrading you, controlling the relationship;

3) low self-esteem;

4) the need for constant encouragement and support from others to feel that you have everything going well;

5) feeling of powerlessness to change anything in destructive relationships;

6) The need for alcohol, food, work, sex or any other external stimulants to distract from their experiences;

7) the uncertainty of psychological boundaries;

8) a sense of himself as a martyr;

9) a sense of himself as a buffoon;

10) inability to feel true intimacy and love.

Thus, codependent people only superficially give the impression sverhotvestvennyh people, but they are equally irresponsible for his fortune, for their own needs for their health and can not be good parental responsibilities. In a separate consideration of needs, in our opinion, the study of psychology in the state of the problem codependent personality. In this context, exploring the family and its problems, we believe it is necessary to take an interest in the early development of its me E. Byrne argued that the foundation of life plan, is formed largely under the influence of parent to child relationship and occurs before birth (Bern, 1972). The study of co-dependence at different stages of childhood and adulthood is important for understanding age-related patterns of emotional person, becoming its emotional and personal education. It was co-dependence, as noted by many researchers (K. Horney, 1950 E. Byrne. 1992; VM Astapov, 2000; M. Beatty, 1986; Moskalenko VD, 1991-2000; T. P. Korolenko NV Dmitrieva, 2000-2003, etc.), forms the basis of a number of psychological problems of childhood, including many developmental disorders [5].

Codependency is considered as an indicator of "prenevroticheskogo state", its role is extremely high and in violation of conduct. The importance of prevention of codependency, it is important to address in preparing children and adults in difficult life situations, and when learning a new activity (N. Dmitrieva, 2001). An essential complement to all of the above classifications is that codependency may exist as an isolated syndrome, and appear in other disorders. Traditionally, the priority in the study of co-dependence, in terms of psychology belongsAWSchaef. This fact, however, is not a basis to assert that to AWSchaef (1986, p.105), none of the authors (philosophers, psychologists) IDP not address the topic of codependency. Great influence on the development problems of codependency have views of P. Mellody C. Hurcom, C. Black, M. Beattie, P.Potter-Efron.

In spite of sufficient research interest in this problem, the scientific literature remains a lot of things are not clarified, as in the understanding of this very phenomenon, and those aspects that are related to its correction. Work is devoted to the comparative expression of co-dependence in different periods of childhood and its impact on personality development, isolated (M. Beatty, 1997; N. Iwaniec, 1988, LD Miroshnichenko, 2001; Moskalenko VD 1996; T .M. Mishina, 1983; AK Myager AI Zakharov, 1987, 1988, VR Kislovskaya, 1972 Astapov VM, 2001). Thus, we come to defining essence of the phenomenon, designated above as "codependent personality state." Codependent state identity individually psihologcheskie human characteristics, largely coinciding with a dependent personality disorder and is characterized as follows (NV Dmitrieva, 2001):

1) inability to make everyday decisions without assistance from,

2) a compromising position,

3) failure to prepare and implement their own plans and initiatives,

4) the desire to create the impression,

5) desire to control, egocentrism,

6) suppressed emotions, fear and anxiety.

"It is important to understand that codependency is a more severe form of addiction, addiction than to a specific activity or agent. The favored model is based on the co-dependent formal - logic, which does not fit into reality. We addicts in some stage of addiction, a new addictive personality, which has its own system of values within the addictive personality takes a complete logical structure that exists on the background and same personality. It should be emphasized that in cases of severe codependency old person, as a rule, is also addictive. The impression is that the core of any addiction is codependency, which provokes the development of other addictions. " Dmitrieva N.D. (2001).

\section{Results}

At the the pilot study stage we considered the following tasks:

1. Comparison of theoretical and practical material on the impact of co-dependence on the behavioral activity of the 
individual.

2. The final choice of methods of psycho-diagnostics co-dependent states with a view to their use in experiments.

3. Sampling and testing of means of psychological adjustment of codependency: verbal (social-psychological training, family portrait, social drama) and nonverbal (family sculpture, family choreography, role-playing card game).

4. Data analysis.

A number of observations were held on subjects of different age groups. The main purpose of this observation was to identify common behavioral and psycho-vegetative reactions that localize co-dependent wife. This study poses insider's view on the behavior of women, which allows to identify specific behavioral responses, the organization of their interaction with other people and, if possible, psycho-vegetative reactions. The observation was carried out in the experimental group on the first day of the seminar.

To obtain objective data we conducted a three-section observations in each of these age groups. For carrying out the sections in each group (for each stage), the events with similar content were selected:

1) Meeting in training groups (the acquisition of psychological knowledge, skills, and communication skills, correction of communicative settings, etc.);

2) weekly two-hour phychocorretive session, which lasted for six months (this stage of the training program includes sections: the introduction of the concept of swinish parent swinish by K. Steiner);

3) working with verbal and non-verbal cues emanating from the ego-states (by E. Byrne);

4) observation of the respondents during short breaks and in their free time activities through joint unincorporated (simple) observation.

While development of methods for observing behavioral reactions and interactions of women, we have relied on the principles of supervision as it was set out by Moskalenko V.D. (1990).

The typical manifestations of signs of increased nervous tension, anger, situational anxiety, fear and guilt were found. This study involved 92 women (wives husbands of which have alcohol problems).

The summarized results of our observations are given in the annexes.ITO (modified version).The results of the present test are shown in Table 3.

The study used the scale of the test MMPI: C (Correction) иНс (Hysterical chorea). The results are shown in Table 4.

IDP data (The Interpersonal Diagnosis of Personality by Leary T.) allowed to find a new approach to the problem of self-esteem, criticism and self-identity, and greatly enriched the social-psychological study of small groups. The results of the present test are shown in Table 5. This study used a scale of "Introversion". The method is designed to study the style and structure of interpersonal relationships and their characteristics, as well as the study of representations of the subject himself, his "ideal self", the attitude to oneself. Based on the research of interpersonal relationships, T. Leary identified 8 common: imperious - a leading, independent the dominant, aggressive, suspicious - skeptical, dutifully shy, dependent, collaborating, altruistic, and 16 more specific variants of interpersonal interaction. The questionnaire is made according to these selected types of interpersonal behavior and is a collection of 128 simple, concise characteristics of epithets, which are grouped into 16 questions that reflect different psychological profiles. Assessing yourself on items of the questionnaire, the subject has to mark "+" on those characteristics that are inherent to consider themselves. The results of the present test are shown in Table 6. This study used a scale of "Aggression".

As mentioned above, the scale related to the subject of this research were identified for each of the questionnaire..Then, the correlation coefficient was calculated for the following pairs of scales:

1. Aggression(Leary T.)-Dependence (Q-gradation).

2. Aggression (Leary T.)-Feeling of guilt («Incomplete sentences»).

3. Aggression (Leary T.) - (Dependence) (ITQ).

4. Aggression (Leary T.) - Hc (Hysterical chorea) (MMPI).

5. Aggression (Leary T.) - Introvesion (IDP).

Table 1. The correlation between the test methods scales

\begin{tabular}{|c|c|c|c|c|c|}
\hline$X$ & Y & $\mathrm{Rx}$ & Ry & $\mathrm{d}$ & $d^{2}$ \\
\hline 7 & 6 & 3 & 5,5 & $-2,5$ & 6,25 \\
\hline 5 & 5 & 5 & 7 & -2 & 4 \\
\hline 3 & 8 & 9 & 1 & 8 & 64 \\
\hline 4 & 7 & 7 & 3 & 4 & 16 \\
\hline 4 & 7 & 7 & 3 & 4 & 16 \\
\hline 6 & 3 & 4 & 8,5 & $-4,5$ & 20,25 \\
\hline 9 & 2 & 1 & 10 & -9 & 81 \\
\hline 4 & 3 & 7 & 8,5 & $-1,5$ & 2,25 \\
\hline 8 & 7 & 2 & 3 & -1 & 1 \\
\hline 2 & 6 & 10 & 5,5 & 4,5 & 20,25 \\
\hline \multicolumn{6}{|c|}{$p=-0,4$} \\
\hline
\end{tabular}

$X$ - aggressive (Leary T.)

$\underline{Y}$ - dependence (Q-gradation)

Analysis of the results of the study showed that aggression as a manifestation of anger is inversely associated with moderate scales of "dependence" (Q-gradation) $p=-0,400$ and introversion (IDP) $\mathrm{p}=-0,376$. 
Table 2. The correlation between the test methods scales

\begin{tabular}{|c|c|c|c|c|c|}
\hline$X$ & $\mathrm{Y}$ & $\mathrm{Rx}$ & Ry & $\mathrm{d}$ & $\mathrm{d}^{2}$ \\
\hline 7 & 1 & 3 & 3 & 0 & 0 \\
\hline 5 & -2 & 5 & 8 & -3 & 9 \\
\hline 3 & -2 & 9 & 8 & 1 & 1 \\
\hline 4 & 0 & 7 & 4,5 & 2,5 & 6,25 \\
\hline 4 & 2 & 7 & 2 & 5 & 25 \\
\hline 6 & 0 & 4 & 4,5 & $-0,5$ & 0.25 \\
\hline 9 & -1 & 1 & 6 & -5 & 25 \\
\hline 4 & -3 & 7 & 10 & -3 & 9 \\
\hline 8 & 3 & 2 & 1 & 1 & 1 \\
\hline 2 & -2 & 10 & 8 & 2 & 4 \\
\hline
\end{tabular}

$X$ - aggressive (Leary T.)

Feeling of guilt («Incomplete sentences»)

The data presented in the table allow to draw a conclusion that the wrath of both affective - cognitive and activity factor is highly associated with the scale of "guilt" ("incomplete sentences") $p=0,512$

Table 3. The correlation between the test methods scales

\begin{tabular}{|c|c|c|c|c|c|}
\hline $\mathrm{X}$ & $\mathrm{Y}$ & $\mathrm{Rx}$ & $\mathrm{Ry}$ & $\mathrm{d}$ & $\mathrm{d}^{2}$ \\
\hline 7 & 7 & 3 & 4 & -1 & 1 \\
5 & 4 & 5 & 7,5 & $-2,5$ & 6,25 \\
3 & 1 & 9 & 10 & 4,1 & 1 \\
4 & 3 & 7 & 9 & -2 & 4 \\
4 & 5 & 7 & 6 & 1 & 1 \\
6 & 8 & 4 & 1,5 & 2,5 & 6,25 \\
9 & 8 & 1 & 1,5 & $-0,5$ & 0,25 \\
4 & 7 & 7 & 4 & 3 & 9 \\
8 & 4 & 2 & 7,5 & $-5,5$ & 30,25 \\
2 & 7 & 10 & 4 & 6 & 36 \\
\hline
\end{tabular}

$\mathrm{X}$ - aggressive (Leary T.)

Y-Dependence) (ITQ).

The data presented in the table allow to draw the conclusion that the wrath of both affective and cognitive and activity factor is highly associated with scale (dependence) (ITQ) $\mathrm{p}=0,424$, which means that its relationship with increased self-control, especially if it occurs due to feelings of guilt.
Table 4. The correlation between the test methods scales

\begin{tabular}{|c|c|c|c|c|c|}
\hline $\mathrm{X}$ & $\mathrm{Y}$ & $\mathrm{Rx}$ & $\mathrm{Ry}$ & $\mathrm{d}$ & $\mathrm{d}^{2}$ \\
\hline 7 & 7 & 3 & 3 & 0 & 0 \\
5 & 7 & 5 & 3 & 2 & 4 \\
3 & 6 & 9 & 6,5 & 2,5 & 6,25 \\
4 & 4 & 7 & 10 & -3 & 9 \\
4 & 6 & 7 & 6,5 & 0,5 & 0,25 \\
6 & 5 & 4 & 9 & -5 & 25 \\
9 & 6 & 1 & 6,5 & $-5,5$ & 30.5 \\
4 & 7 & 7 & 3 & 4 & 16 \\
8 & 6 & 2 & 6,5 & $-4,5$ & 20,5 \\
2 & 8 & 10 & 1 & 9 & 81 \\
\hline
\end{tabular}

$\mathrm{X}$ - aggressive (Leary T.)

Y -Hc (Hysterical chorea )(MMPI)

The data presented in the table allow to draw a conclusion that the wrath of both affective and cognitive and activity factor has little to do with the factor of "hysteria» (MMPI) $p$ $=-0,164$, indicating that the inner nature of the mechanisms of its effects on the social interaction between the individual.

Table 5. The correlation between the test methods scales

\begin{tabular}{|c|c|c|c|c|c|}
\hline $\mathrm{X}$ & $\mathrm{Y}$ & $\mathrm{Rx}$ & $\mathrm{Ry}$ & $\mathrm{d}$ & $\mathrm{d}^{2}$ \\
\hline 7 & 7 & 3 & 5 & -2 & 4 \\
5 & 5 & 5 & 6 & -1 & 1 \\
3 & 8 & 9 & 2,5 & 6,5 & 42,25 \\
4 & 4 & 7 & 7,5 & $-0,5$ & 0,25 \\
4 & 8 & 7 & 2,5 & 4,5 & 20,25 \\
6 & 3 & 4 & 9,5 & $-5,5$ & 30,25 \\
9 & 3 & 1 & 9,5 & $-8,5$ & 72,25 \\
4 & 4 & 7 & 7,5 & $-0,5$ & 0.25 \\
8 & 8 & 2 & 2,5 & $-0,5$ & 0,25 \\
2 & 8 & 10 & 2.5 & 7,5 & 56.25 \\
\hline
\end{tabular}

$X$ - aggressive (Leary T.)

Y-Introvesion (IDP)

The data presented in the table allow to draw a conclusion that aggression as a manifestation of anger is associated inversely with moderate scales of "dependence» (Q-gradation) $\mathrm{p}=-0,400$ and introversion (DMO) $\mathrm{p}=-0,376$. This indicates that the manifestations of anger in social interaction of personality are external in nature and aimed at the acquisition of personality more autonomy from the surrounding social environment.

The preliminary actions for Spierman coefficient 
correlation calculations and the counted coefficients for each of the selected pairs of scales are shown in the Tables $(1,2,3,4,5)$.

The results of the pilot study revealed that the level of co-dependent conditions of the person slightly depending on sex, age, and education.

Table 6. In the calculations the total Spearman (p) order correlation coefficient on the scales indicated in the table was used

\begin{tabular}{|c|c|c|}
\hline Номер & Scales & $\begin{array}{c}\text { Spearman } \\
\text { correlation } \\
\text { coefficient }\end{array}$ \\
\hline 1. & $\begin{array}{c}\text { Aggression (Leary T.)-Dependence } \\
\text { (Q-gradation) }\end{array}$ & $-0,400$ \\
\hline 2. & $\begin{array}{c}\text { Aggression (Leary T.)-Feeling of guilt } \\
\text { («Incomplete sentences») }\end{array}$ & 0,512 \\
\hline 3. & Aggression (Leary T.) - (Dependence) (ITQ) & 0,424 \\
\hline 4. & $\begin{array}{c}\text { Aggression (Leary T.) - Hc (Hysterical chorea) } \\
\text { (MMPI). }\end{array}$ & $-0,164$ \\
\hline 5. & Aggression (Leary T.) - Introvesion (IDP) & $-0,376$ \\
\hline
\end{tabular}

$$
p=1-\frac{6 E d^{2}}{N\left(N^{2}-1\right)}
$$

where $\mathrm{N}$-number of contrasted pairs of values of two variables,

d - squared differences of ranks of these variables.

Conducted pilot study of co-dependent conditions of the individual allowed to highlight the presence of the subjects of psychological problems following:

1. The presence of psychologic traumatic experience

2. Development of certaintraits of character in the family.

3. Lack of social support from the surround.

4. The difficulties in the ability to overcome difficulties.

5. Inappropriate choice of marriage partner.

6. Co-residence with alcohol addicted person.

Defining the concept of "codependency," it should be noted that it occupies an important place, both in psychology and in philosophy, sociology, medicine (psychiatry, psychotherapy, psychosomatic medicine, etc.). Such an interest in this concept by experts in various fields of knowledge began to emerge since, as Freud in several papers (for example, «Hemmung, Simptom und Angst», 1926) emphasized its important role in the occurrence of neuroses. In his early works, he held the view that anxiety (an important characteristic of codependency) is a consequence of the transformed libido, recognizing, however, later that she is a reaction to danger. It was Freud ascribed priority in recognizing the fundamental importance of the problem of anxiety. It was he who examined anxiety as a basic phenomenon, an understanding which is necessary to analyze the emotional and psychological disorders. R. May argues that Freud's views "on the problem of anxiety has evolved over a lifetime."

With all the attention to the issue of codependency or in psychology or sociology, or medicine, and there is still no single working concept, which would suit all professionals. However, the vast majority of the definitions of this concept is very similar to each other and, in some measure, repeat, and both complement each other. findings 1 . Codependency is important in the study of individual to individual. The problem of co-dependence is one of the most complex and is actively being studied. This is due to the exceptional role of co-dependence in the formation of individuality personality and its role in the interaction of the subject with the world and close relationship with his mental and physical health $[15,16]$.

Research with a certain accuracy divorced concepts such as "dependence" and "codependency." This approach is due to the fact that these phenomena are similar in nature have a number of significant differences, which must be considered when conducting remedial actions. 3. Under the co-dependent state of the individual, we understand the constant concentration of thought on someone or something and emotional, social, physical dependence on a person or object. Sometimes this dependence on another person becomes a pathological condition that affects all other relationships. 4. There are biological, psychological, social, spiritual development and the causes of codependency. Conventionally, they can be divided into physiological, genetic (biological) predetermined, hereditary causes and sources, ie those that are individual to the beginning, as well as on the social sources and causes that lead to the emergence and development of codependent personality states resulting from the interaction of the individual in a social environment [17].

Virtually all experts in some way related to the study of codependency, codependents recognize a significant impact on the effectiveness of individual states and the quality of the individual's emotional state, self-esteem, adaptation, physical health. Its behavioral effects are inadequate: the withdrawal of combat (up to a different kind of "care": a disease, alcoholism, drug addiction, etc.) aggression, which raises new challenges for codependents, hidden behaviors such as stealing, lying (reaching sometimes to the point of pathological lying), a hidden vengefulness, etc. Analysis of the literature suggests the need for correction states codependent personality $[18,19]$. This is necessary for the normal, appropriate personal development, its adaptation to the environment in which is its vital.

\section{Discussion}

The specialists' attention to codependency was called in the 70 years of the twentieth century. At that time the first major study on the psychological state was published. To some extent the problem of codependency in foreign science was studied by M. Beattie, C. Dlack, J. Bradshaw, S. Covey, W. Feuerlein, S. Karpman,, C. Hurcom, P. Mellody, 
A.Miller and other researchers.In our country, codependency has been actively studied in $80 \mathrm{~g}$.g. of the twentieth century. However, the number of studies was clearly inadequate for having a clear presentation on this phenomenon. In recent years, interest to co-dependence of the local researchers become more tangible, but, despite this, in the available literature there are no scientific works (monographs, thesis research paper) adequately covering various aspects of the problem we are considering. These studies were conducted at different times by M. Beatty, Iwaniec N., Moskalenko V.D.,Korolenko C.S., Dmitriev N.V.,Nuznyi V.P, Smith E.W. e.t.c.

Analyzing the psychoanalytic concept of co-dependence, particularly the reasons for its occurrence, and Ts.P.Korolenko N.V. Dmitrieva (2003) point out that, according to this theory, in the later periods of life for a person associated with the occurrence of co-dependency violation of the principle of pleasure as a result of locking mechanisms of biological stress reduction. This leads to stag nation, lack of sexual drive unloading. If such a discharge does not occur, the psychic tension appears. The choice of the research topic and the age group of subjects (wife which husbands suffer from alcohol addiction) involved in the experimental work, is not accidental, because as the practice shows that the most serious problems in terms of social contacts have co-dependence because of anxious expectations of failures in communication, especially in their new situations, groups and collectives. Moreover, the fear of losing control over the situation, co-dependent themselves fall under the control of events or their family.

\section{REFERENCES}

[1] Arguelles, Jose. 1987. The May an Factor. Santa Fe: Bear \& Co.

[2] Beattie M. The alcoholic in the family, or to overcome codependency. M., 1997.

[3] Beattie, Melody. 1987. Co-dependent No More. New York: Harper \& Row.

[4] Black, Claudia. 1981. It Will Never Happen to Me. Denver, CO: M.A.C. Printing and Publication Division.
[5] Dear G.E., \&. Roberts C.M. The Holyoake Codependency Index: Investigation of the factor structure and psychometric properties. Psychological Reports, Vol. 87, 991-1002, 2000.

[6] Fingarette, Herbert. 1988. Heavy Drinking: The Myth of Alcoholism as a Disease. Berkeley, CA: University of California Press.

[7] Griffin, Susan. 1978. Woman and Nature. New York: Harper \& Row.

[8] Halpern, Howard. 1982. How To Break Your Addiction To A Person. New York: McGraw-Hil Book Company.

[9] Kaplan, Louise J. 1978. Oneness and Separateness: From Infant to Individual. New York: Simon and Schuster.

[10] Karpman, Steven. 1968. "Fairytales and Script Drama Analysis", Transitiona Analysis Bulletin. 7:39-43.

[11] Miller, Alice. 1983. For Your Own Good. New York: Farrar, Straus, Giroux.

[12] Schaef, Anne Wilson. 1986. Co-Dependence Misunderstood-Mistreated. New York: Harper \& Row.

[13] Schiff, Jacqui, et al. 1975. The Cathexis Reader. New York: Harper \& Row.

[14] Subby, Robert. 1984. "Inside the Chemically Dependent Marriage: Denia Manipulation", in Co-Dependency: An Emerging Issue. Pompano Beach, FL: Health Communications.

[15] Korolenkocs, DmitrievaN.V.Sotsiometricheskaya psychiatry. - New York: Academic Project, Yekaterinburg: Business Book, 2000.

[16] Korolenko TS.P., Dmitrieva NV, Zagoruiko EN Identity. Novosibirsk, 2007. 472s.

[17] Moskalenko.V.D. The social work with families of alcoholics. Moscow, 1992.

[18] Miroshnichenko, LD Addiction encyclopedia in two parts. M., 2001.

[19] Ruehling P.V., Koelbe N. 1, \& Rutgers C.. Codependence and conduct disorder: Feminine and masculine coping responses to abusive parenting practices. Sex Roles, Vol. 35, 603-618, 1996.

[20] Cloud, G., J. When Taundsen say YES. When to say NO. Spb., 1999.

[21] Young E Co alcoholism as a disease implications for psychotherapy / / J Psychoactive Drugs - 987-Vol 19 N3-P 257268. 